\title{
Dynamic Response of Power Conditioning Systems for Superconductive Magnetic Energy Storage
}

\author{
R. H. Lasseter, Senior Member, IEEE \\ University of Wisconsin-Madison \\ Dept of Electrical and Computer Engineering \\ 1415 Johnson Drive \\ Madison, WI 53706
}

\begin{abstract}
The dynamic response of two new power conditioning systems for Superconductive Magnetic Energy Storage (SMES) are presented. One power conditioning system is based on a hybrid current sourced inverter (CSI), the second is a combination of a dc chopper with a voltage sourced inverter (VSI). The response of both systems to a load change, a three phase fault and start-up is presented in this paper.
\end{abstract}

Keywords: SMES, Energy Storage, Power Conditioning, Hybrid CSI, Chopper, VSI.

\section{Introduction}

Two different power conditioning systems for the superconductive magnetic energy storage (SMES) system are presented in reference [1]. The first proposed system is a hybrid CSI. In this scheme, parallel CSIs allow for the distribution of the SMES current and the GTO based inverters allow the system to have independent control of the real and reactive power. In addition the hybrid scheme uses one transformer to link the two parallel converters which limits the transformer rating to the maximum delivered power level.

The second proposed system is a combined VSI-Chopper system. This system uses a DC-DC converter coupled with a VSI to solve the high converter rating problem associated with SMES applications. The VSI provides four quadrant operation with the ac system while the chopper controls the dc current and voltage levels.

The Electro Magnetic Transient Program,(EMTP) is used for simulating the dynamic behavior of both proposed systems [2]. The events studied are changes in AC load, response to $\mathrm{AC}$ faults and the start-up procedure.

Figure 1 shows the general configuration of the simulated system. In both cases, a $100 \mathrm{MW}$ inverter module links the SMES coil to a $110 \mathrm{kV}$ AC bus. The AC system is modelled by its Thevenin equivalent with a short circuit ratio (SCR) of 4.0 , where $S C R$ is defined as the ratio of the short circuit MVA of the power system to maximum power transfer. The $\mathrm{AC}$ load is assumed to be of pulsating nature. The load ranges

91 WM 134-7 EC A paper recommended and approved by the IEEE Energy Development and Power Generation Committee of the IEEE Power Engineering Society for presentation at the IEEE/PES 1991 Winter Meeting, New York, New York, February 3-7, 1991. Manuscript submitted September 5, 1990; made available for printing January 16, 1991.

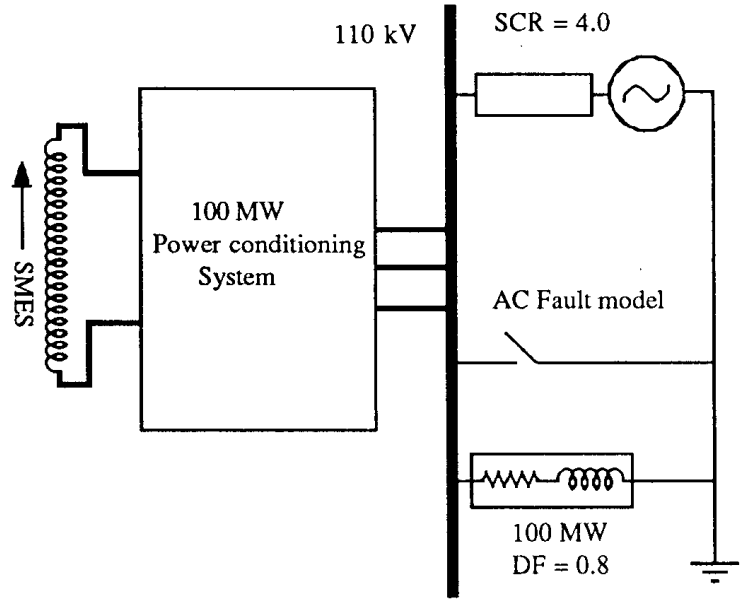

Figure 1 General configuration of the simulated systems

from a minimum level of $50 \mathrm{MW}$ and a maximum of 100 MW. The displacement factor of the load is assumed to be 0.8 lagging at all power levels. On the DC side, the SMES coil is modelled as an inductor with zero resistance. The coil current is assumed to range from a maximum of $50 \mathrm{kA}$ to a minimum of $15 \mathrm{kA}$. The coil voltage levels can be any value between $6.6 \mathrm{kV}$ and $-6.6 \mathrm{kV}$.

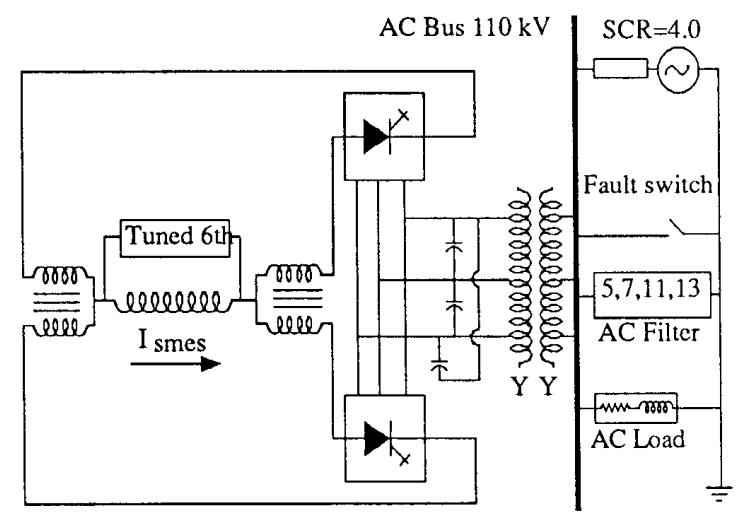

Figure 2 Simulation model of a $100 \mathrm{MW}$ hybrid CSI 


\section{IIybrid CSI}

Figure 2 shows the model for a $100 \mathrm{MW}$ hybrid CSI. This converter consists of two 6-pulse, $50 \mathrm{MW}$ GTO bridges connected in parallel. They used a single transform and delta connected capacitors to reduce cost. The capacitors help limit switching overvoltages and provide a commutation path for GTO turn off. Since the hybrid system is modeled as a 6-pulse system, tuned 5th, 7th, 11th and 13th AC filters are used on the $A C$ side. On the DC side, the inverters are connected in parallcl through two sets of coupled reactors to insure current sharing. A 6 th harmonic filter is used to reduce the voltage distortion across the SMES coil.

\section{Control Algorithm for the Hybrid CSI}

The control algorithm for the system is assumed to be open loop for the real and reactive power $(\mathrm{P}$ and $\mathrm{Q})$ demands of the $\mathrm{AC}$ system. Figure 3 shows the control block diagram of the simulated system. The inputs are the real power $(P)$, the displacement factor of the AC load (DF), the coil current ( $\mathrm{I}_{\text {smes }}$ ) and the $\mathrm{AC}$ bus voltage (V). The outputs are the firing angle delays of the two inverters which are represented by $\alpha 1$ and $\alpha 2$. The $\mathrm{L}$ and $\mathrm{C}$ represent the leakage inductance of the Iransformer and the commutation capacitors of the hybrid converter respectively. The capacitance of the filters and the inductance of the AC system are neglected. For derivation of the cquations refer to reference [1].

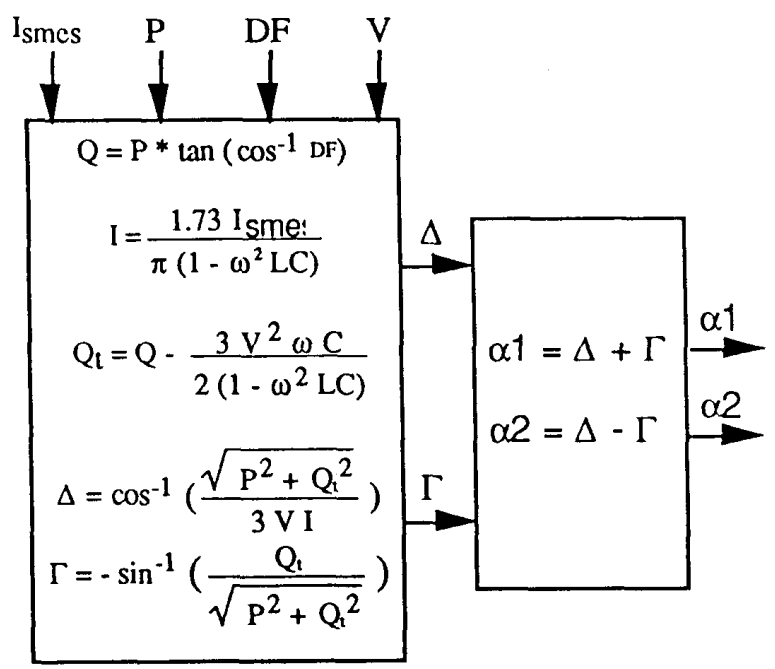

\section{Figure 3 The control block diagram}

In principle the firing angle delays, $\alpha 1$ and $\alpha 2$ must be referenced, or synchronized, to the $\mathrm{AC}$ bus voltage. In these studics, the firing signals are synchronized to the positive sequence of the fundamental component of the $\mathrm{AC}$ voltage to avoid harmonic problems. The synchronizing circuit calculates the Fourier coefficients corresponding to the positive sequence of each phase by integrating each over the last half cycle [2]. This positive sequence component is then used as an $\alpha=0$ reference for calculating the correct firing time for each GTO.

Dynamic Response to AC load changes.

The most basic event is a change in the AC load demands. In this case, the real power demanded is assumed to drop from
10) $\mathrm{MW}$ to 50 MW and then returns to $100 \mathrm{MW}$ two hundred milliseconds later while the displacement factor of the load is kept constant at 0.8 . Figure 4 shows the response to the load change.
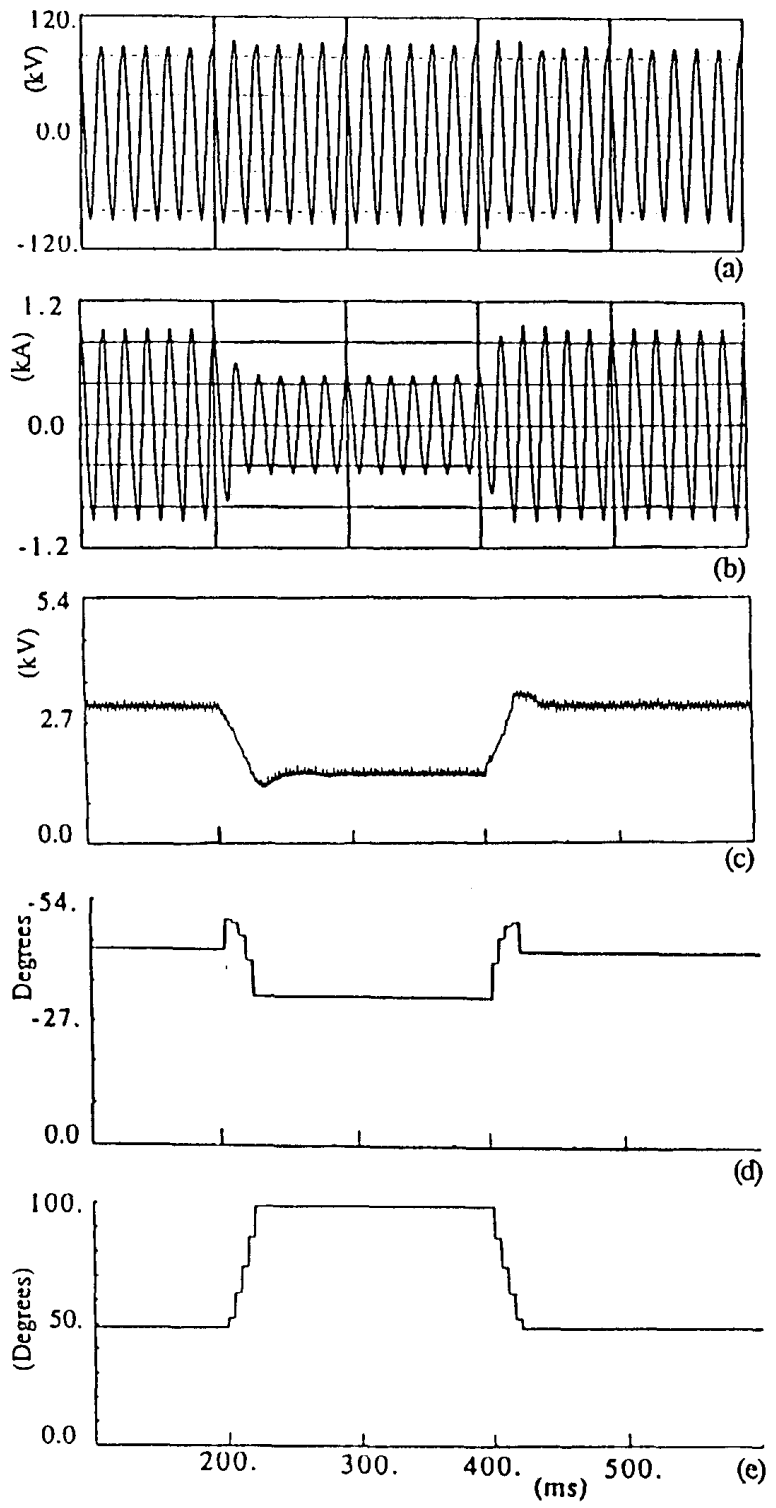

Figure 4 Dynamic response to load change

a) Phase a vollage

b) Phase a load current

c) DC voltage across the SMES coil

d) Firing angle delay of inverter one

e) Firing angle delay of inverter two

Figures $4 \mathrm{a}$ and $4 \mathrm{~b}$ show phase a bus voltage and load current. Figure $4 \mathrm{c}$ shows the DC voltage across the SMES coil. The coil current for this study is constant at $30 \mathrm{kA}$. As expected, the coil voltage and ac current reflect the drop in the real power demand.

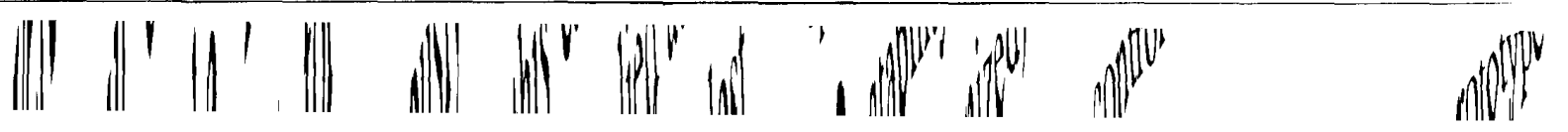


Figures $4 \mathrm{~d}$ and $4 \mathrm{e}$ show how $\alpha 1$ and $\alpha 2$ change as the power demanded changes. As can be seen from figure $4 d$, the first converter is supplying $P$ and $Q$ both before and after the change in the load demand. However, the magnitude of the $Q$ provided by this converter is decreased as the AC load drops by one half. Note that as the AC load demand drops, the amount of the reactive power supplied by the delta capacitors remains constant resulting in the reduction of $Q$ provided by converter one. Figure $4 \mathrm{e}$ shows that the second converter is supplying $P$ to the load and consuming $Q$ before the change in the $A C$ load. After the AC load drops, it consumes both power and reactive power from the ac system.
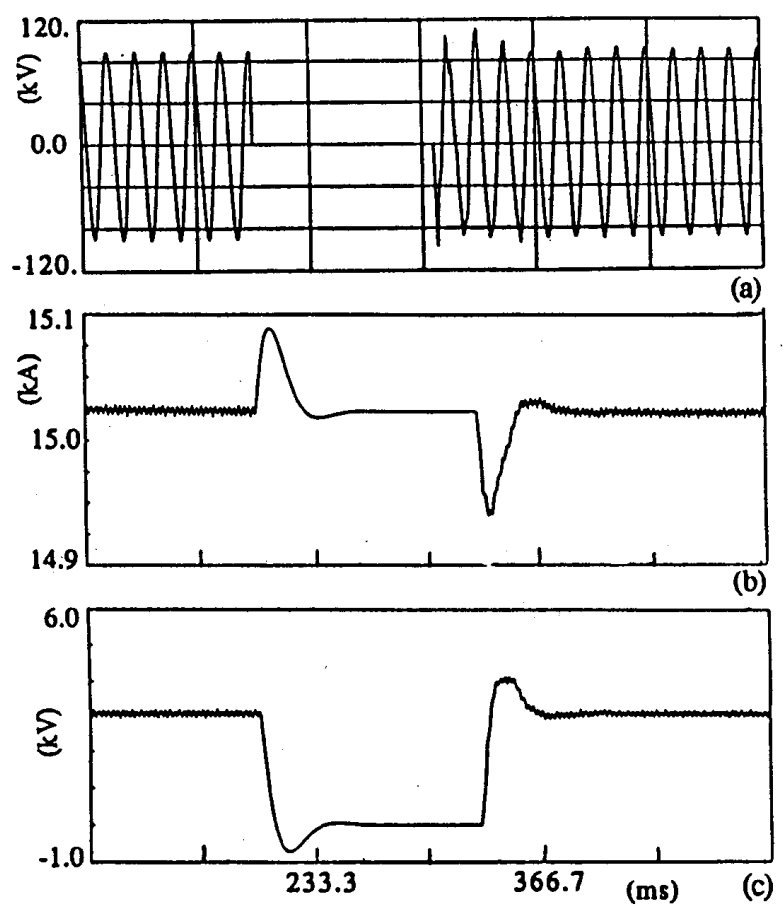

Figure 5

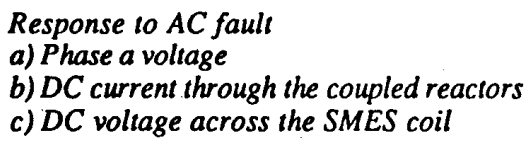

Response of the Hybrid CSI to Faults

Figure 5 shows the response of the system to a three phase AC fault. The fault occurs at $200 \mathrm{~ms}$ with a duration of 100 $\mathrm{ms}$. Figure 5a shows that the AC bus voltage is shorted during this period. Figure $5 \mathrm{~b}$ shows that the disturbance to current balance in the coupling reactors is less that $1 \%$ which returns to the balanced case in a few milliseconds. Figure $5 \mathrm{c}$ shows the DC voltage across the coil.

As soon as the fault occurs, both of the CSIs bypass allowing the DC current to circulate through the GTOs. This is achieved by closing one pair of the valves connected to the same phase while opening the other two sets of valves connected to the other two phases in each converter. In this bypass mode, each of the CSIs look like a short circuit to the DC current sharing reactors and an open circuit to the AC delta capacitors. Figure $5 \mathrm{~b}$ shows that the DC current through each converter remained constant through $\mathrm{AC}$ fault. Once the $\mathrm{AC}$ fault is cleared, the two CSIs are taken out of the bypass mode and continue their normal mode of opcration.

Opening the Shorting Switch with the Hybrid CSI In a storage mode the SMES coil current is circulating through a shorting switch. To provide power to the $A C$ system the current of the coil must be transferred from the shorting switch to the converter as part of the start-up procedure.

Figure 6 shows how the system responds to this start-up procedure. In this figure, the hybrid converter operates as a rectifier from $10 \mathrm{~ms}$ to $14 \mathrm{~ms}$. This operation uses power from the ac system to drive a counter current in the shorling switch which slowly brings the switch current to zero followed by the opening of the switch. During this same period the current sharing reactors achieve their nominal operating levels of current. See the dashed curve in Figure 6. For reactor current levels.

The start-up period ends when the current through the shorting switch reaches zero. At this point, both of the converters are carrying DC current at zero power. The system is realy to provide power to the ac system through the same procedures used in the recovery from a three phase fault.

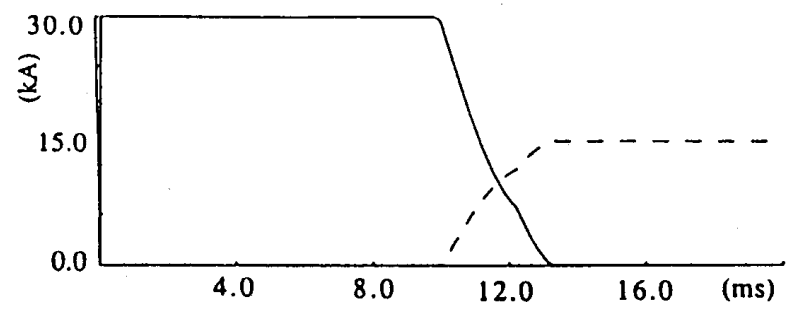

Figure 6

Current through the shorling switch (solid line) and the current through the coupled reactors (dashed lines)

\section{VSI-Chopper}

Figure 7 shows the model for a $100 \mathrm{MW}$ VSI-Chopper system. Power is supplied to the AC system through a voltage sourced inverter (VSI). The VSI is linked to the coil through a de capacitor and chopper. The chopper controls the current llow from the coil to the VSI.

The converter consists of two $50 \mathrm{MW}$ 6-pulse voltage sourced inverters (VSI) connected in scrics on the AC side and in parallel on the DC side. The firing pulses of the two VSIs arc phase shifted 30 degrecs in order to simulated a pscudo 12 pulse VSI system. A pseudo 12-pulse is modelled to study the possible problems which could result from the full pscudo 24pulse system discussed in reference [1].

The chopper is modelled as a two-quadrant three phase chopper with harmonic free duty cycle values of $[0,1 / 3,2 / 3,1]$. Since the concept of harmonic frec points are to be studicd in 


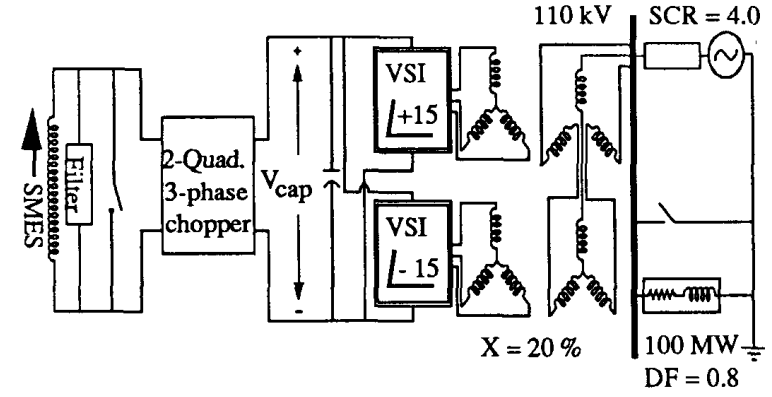

Figure $7 \quad$ Simulation model of a $100 \mathrm{MW}$ VSIChopper system

this case, the system parameters were initially chosen such that a duty cycle value of $1 / 3$ corresponded to $100 \mathrm{MW}$ power operation. Next, the power demanded was halved, which corresponds to a duty cycle value of $2 / 3$.

\section{Control Algorithm for the VSI-Chopper}

The control algorithm of the VSI-chopper system is shown in Figure 8. The inputs are the real power $(\mathrm{P})$, the displacement factor of the AC load (DF), the coil current ( $\left.I_{\text {Smes }}\right)$ and the magnitude of the $A C$ bus voltage $(E)$. The output values are duty cycle of the chopper (D) and $\alpha$ of the VSI. The firing delay $\alpha$ is the angle by which the 12-pulse converter output voltage leads the AC bus voltage. Additional internal variables are $\mathrm{V}_{\text {cap }}, \mathrm{D}_{\text {est }}$ and IVI.

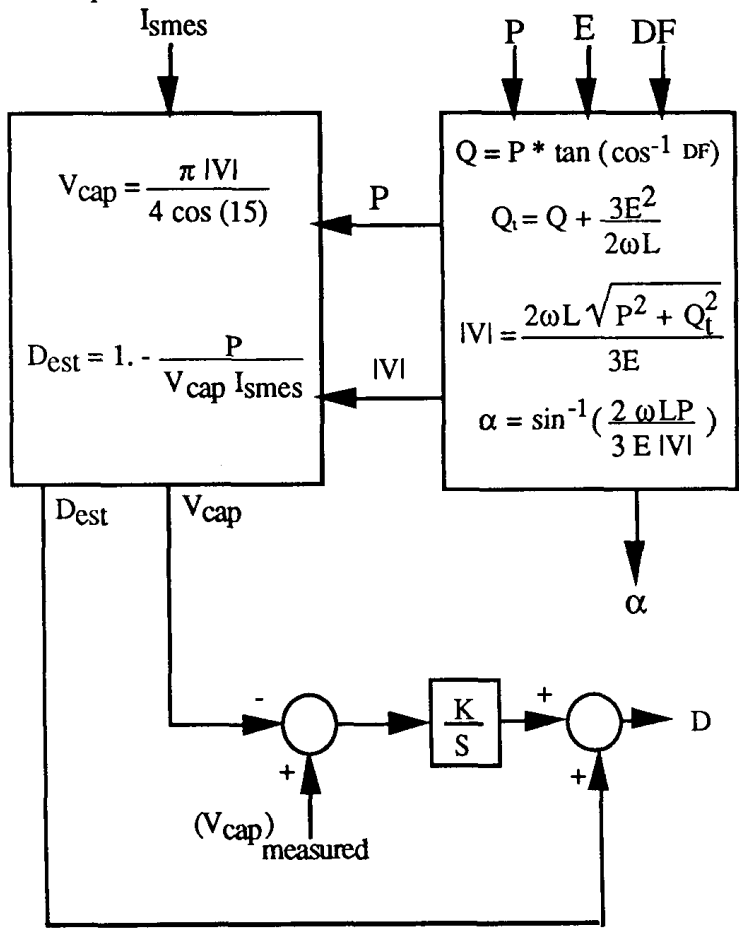

Figure 8 Control block diagram of the VSI Chopper System
$\mathrm{V}_{\text {cap }}$ is the DC voltage across the capacitor coupling the VSI to the chopper. $D_{\text {est }}$ is the estimated duty cycle value of the chopper. $|\mathrm{V}|$ is the magnitude of the converter voltage on the converter side of the transformer. IVI and Vcap are related though the equation shown below. For a pseudo 12-pulse VSI system this equation is derived by adding the equations for a 6-pulse system with phase shifts of +15 and -15 degrees.

$|\mathrm{V}|=\left[2 * \mathrm{~V}_{\mathrm{cap}} / \pi\right] \cos (15)+\left[2 * \mathrm{~V}_{\mathrm{cap}} / \pi\right] \cos (-15$.

The control system is an open loop control on $\alpha$ and closed loop on $V_{\text {cap. }}$. The value of $\alpha$ is calculated directly from the input values resulting in a firing angle which must be synchronized to the fundamental component of the $\mathrm{AC}$ bus voltage. On the other hand, the control system is a closed loop on $V_{\text {cap }}$ to correct for calculation errors in $D_{\text {est }}$. This insures that the DC-DC chopper providing the desired DC voltage across the VSI In the closed loop operation, the valuc of the integrator gain $\mathrm{K}$ is important in determining the dynamics of the system. The value of the gain $\mathrm{K}$ used for simulations was 25.1 , which was found by trial and error.

Dynamic Response to the AC load changes.

In this event, the real power demanded by the AC load drops from $100 \mathrm{MW}$ to $50 \mathrm{MW}$ and then returns to $100 \mathrm{MW}$ two hundred milliseconds later while the displacement factor of the load is kept constant at 0.8 .

Figures $9 \mathrm{a}$ and $9 \mathrm{~b}$ show the $\mathrm{AC}$ bus voltage and $\mathrm{AC}$ load current. Figure $9 \mathrm{c}$ shows the DC voltage across the SMES coil. The coil current for this study is a constant value of 15 $k A$. As expected, the value of coil voltage drops by a factor of two as the real power demanded drops by the same factor. During this event the chopper crosses non-harmonic free points resulting in harmonics in the coil voltage. These harmonics could be avoided in a 58 phase system by constraining the duty cycle to harmonic free points.

Figure 9d shows the duty cycle of the chopper. As the AC load changes, a new value of the duty cycle is calculated using the control system of Figure 7. The underdamped behavior of the duty cycle is due to the closed loop control on $\mathrm{V}_{\text {cap. }}$. As can be seen from Figure 9e the DC voltage across the 12-pulse VSI tracks the reference voltage (shown by the doted curve) with the same underdamped response.

Figure 9f shows $\alpha$ which is the angle by which the 12-pulsc convertor voltage leads the AC bus voltage. The control system is open loop resulting in an $\alpha$ which tracks the change in requested power.

Response of the VSI-Chopper to Faults

Figure 10 shows the response of the system to a three phase AC fault occurring at $300 \mathrm{~ms}$ for $100 \mathrm{~ms}$. Figure 10a shows the AC bus voltage. As soon as the $\mathrm{AC}$ fault occurs all of the GTOs of the VSI are opened as their current becomes zero. This isolates the DC capacitor from the VSI and the AC system. In other words, the VSI looks like an open circuit to this capacitor. This event is represented by the zcro VSI current in figure $10 \mathrm{~b}$.

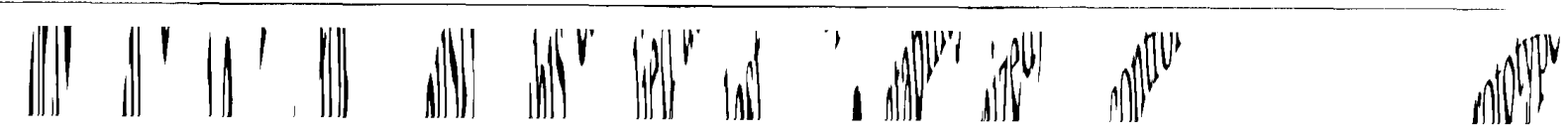


392
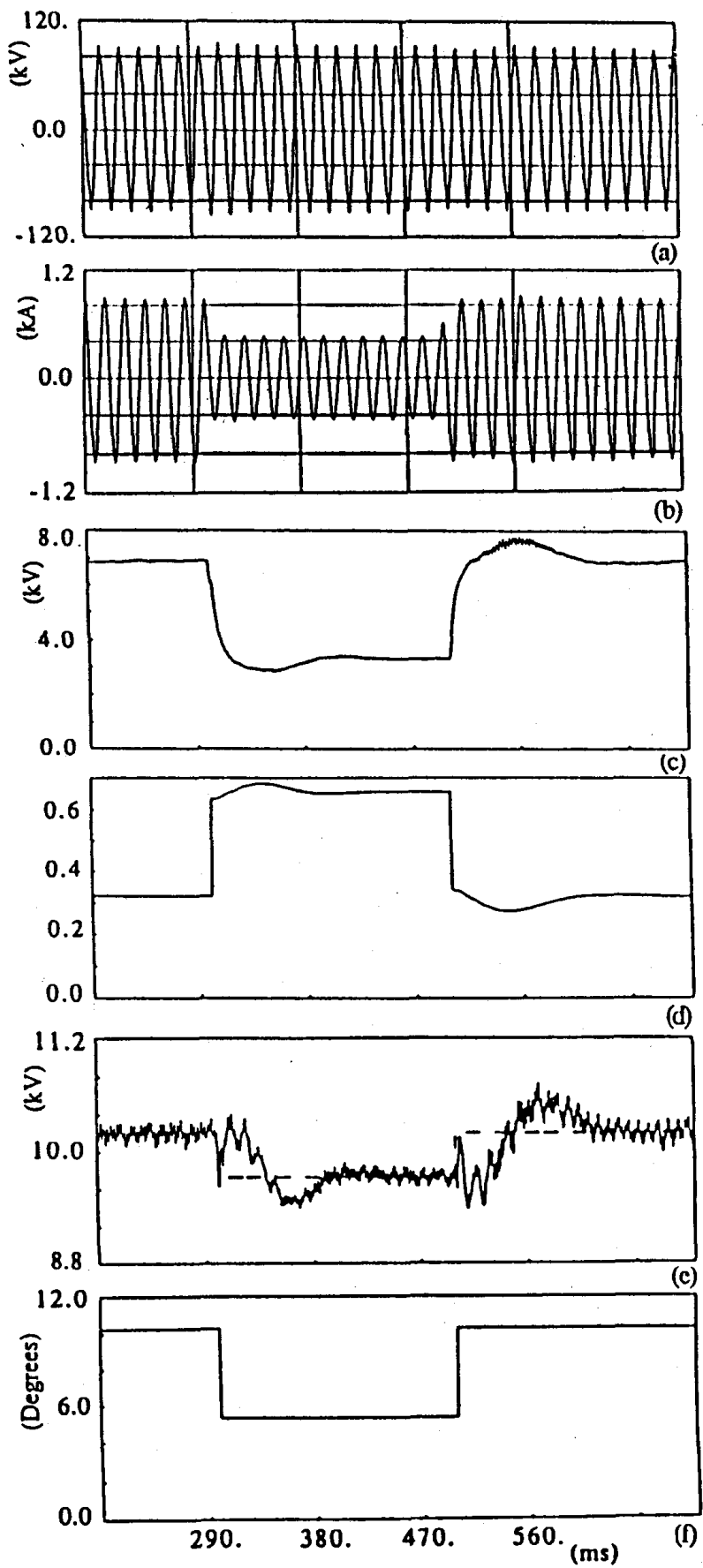

Figure 9
Dynamic response to load change a) Phase a voltage

b) Phase a load current

c) SMES coil voltage

d) Duty cycle of the chopper

e) DC voltage across the 12-pulse VSI

f) Firing angle $\alpha$, of the inverter
At the same time, the chopper shorts the SMES coil by firing one leg of the chopper, which then open circuits the chopper from the DC capacitor allowing the coil current to flow through the chopper legs. Note that the DC voltage across the capacitor in figure $10 \mathrm{c}$ remains charged and becomes harmonics free. However, this capacitor discharges slowly through the snubbers and if the fault remains long enough, the chopper should be used to recharge the capacitor before starting the systcm.

Figure 10d shows the DC voltage across the SMES coil. 'The coil voltage reaches zero during the fault and the dynamics of its transicnt is underdamped thus charging the coil for a short

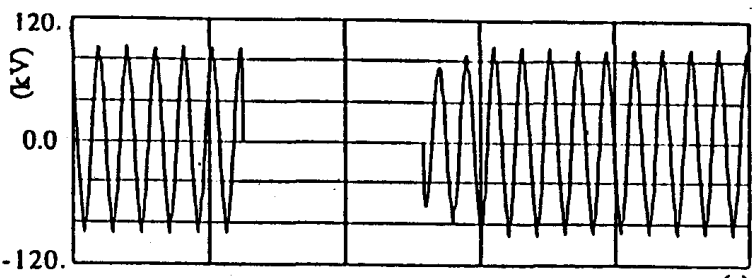

(a)
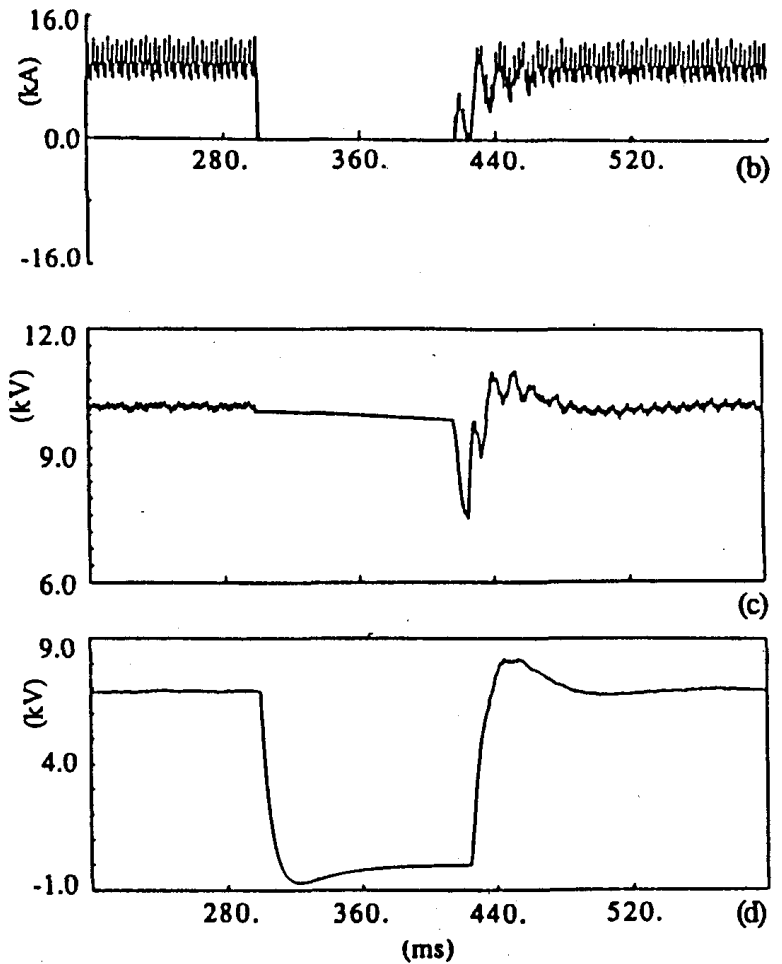

a) Phase a voltage

b) VSI current

c) DC voltage across the 12-pulse VSI

d) SMES coil vollage

time. The energy used to charge the coil comes from the energy stored in the DC capacitor across the coil before the fault occurs. The system recovers from the fault at $400 \mathrm{~ms}$ followed by the VSI and the chopper resuming their normal modes of operation. 
Figure 10c shows that the DC voltage across the capacitor linking the 12-pulse VSI to the chopper. During the restart procedure and the capacitor voltage drops by $25 \%$. This drop is duc to starting the VSI a few milliseconds sooner than the chopper. This drop of the DC voltage is critical in avoiding a large over voltage on the AC side.

Opening the Shorting Switch of the VSI-Chopper Let us look at the storage mode in which the SMES coil current is circulating through the shorting switch. In this case, the current sharing reactors of the chopper carry no current and both the DC capacitor across the 12-pulse VSI and the DC capacitor across the SMES coil are not charged. Now the question is whether the PCS is capable of starting the system quickly without large transients. Figure 11 shows how the modelled system of Figure 7 is capable of this start-up procedure. The DC capacitor linking the VSI and the chopper is initially charged by closing the AC breakers to the 12-pulse VSI. The 12 anti-parallel diodes of the VSI behave like a 12 pulse diode rectifier which charges the capacitor. Figure 11 shows that this charging process takes $9 \mathrm{~ms}$. Note that as soon as the voltage across the DC capacitor becomes greater than the line to line voltage on the AC side the 12 diodes of the VSI become reverse biased ending the charging process.

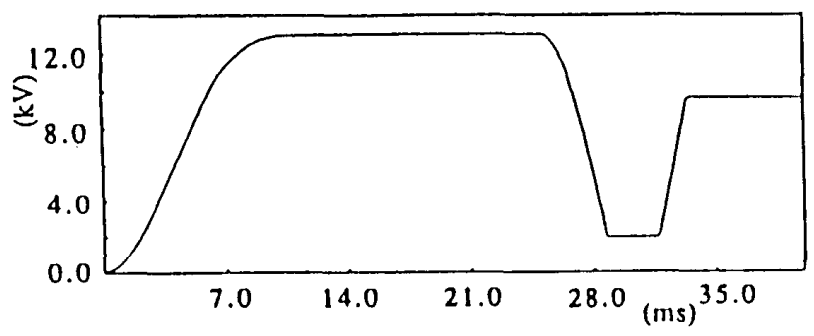

Figure 11 DC voltage across the 12-pulse VSI

Once the DC capacitor is charged, the energy stored in the DC capacitor is used to open the shorting switch. This process starts with the closure of the GTOs of the chopper which then initiates a $3 \mathrm{~ms}$ resonant cycle between the DC capacitor and the current sharing inductors. As a result, the current through the current sharing inductors evenly ramps up and the voltage across the DC capacitor ramps down.

Next, the chopper operates with a duty cycle value of zero for one millisecond in order to recharge the DC capacitor. Upon completion of this cycle, the value of the DC capacitor is charged to the desired value of $10 \mathrm{kV}$. At this point the chopper stops charging the capacitor and the system is ready to go through the saine procedures as in recovery from a threc phase fault.

\section{Conclusion}

The dynamic response of two new power conditioning systems for superconductive magnetic energy storage (SMES) were presented. One power conditioning system is based on a hybrid current sourced inverter (CSI), the second is a combination of a de chopper with a voltage sourced inverter (VSI). The response of both systems to a load change, a threc phase fault and start-up was presented in this paper. Both of the systems showed excellent response. The hybrid CSI is casier to control duc to the presence of only one converter module. On the other hand, the VSI-chopper system allows a better control of harmonics. It is believed that both systems can be useful in future SMES applications.

\section{Acknowledgments}

This work was performed in conjunction with EBASCO Services and Westinghouse Science and Technology Center as part of the Superconducting Magnetic Energy Storage Engineering Test Model Development program. This program is supported by the Defense Nuclear Agency under contract DNA-001-88-C-0027. The authors of this paper also wish to acknowledge that the application of a chopper in series with a voltage sourced inverter was first proposed by the late Peter Wood of Westinghouse Science and Technology Center. Detailed engincering work on this concept by Mr. Kenneth Mattern, of Westinghouse, is also reflected in this paper.

\section{REFERENCES}

(1) R.H. Lasseter,and S.G. Jalali, "Power Condition Systems for Superconductive Magnetic Encrgy Storage, submilted IEEE for WM 91 mecting.

(2) R.H. Lassetcr, "Elcctromagnctic Transicnt Program (EMTP) Workbook IV (TACS)," EPRI EL-4651, Projcct 2149-6, April 1988.

Sasan (i. Jalali received the B.S. degree in electrical enginecring 1988 from the University of Wisconsin-Madison.

Hc is currently working on a M.S. degrec in clectrical cnginecring at the University of Wisconsin-Madison. His interests include power electronics and nonlinear system theory.

Robert H. Lasseter (M'74, SM '89) reccived the Ph.D. degrec in physics at the University of Pennsylvania, Philadelphia, in 1971.

He was a Consultant Enginecr for Gencral Electric Company until he joined the University of Wisconsin-Madison in 1980. He does research in HVdc systems, power electronics, and simulation methods.

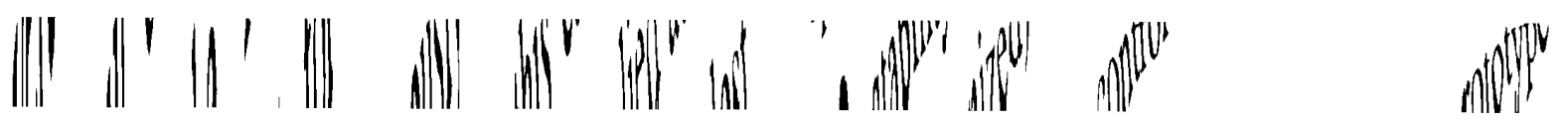

